This item was submitted to Loughborough's Research Repository by the author.

Items in Figshare are protected by copyright, with all rights reserved, unless otherwise indicated.

\title{
Multiphysics modeling approach for micro electro-thermo-mechanical actuator: failure mechanisms coupled analysis
}

PLEASE CITE THE PUBLISHED VERSION

http://dx.doi.org/10.1016/j.microrel.2015.02.012

\section{PUBLISHER}

(C) Elsevier

VERSION

AM (Accepted Manuscript)

\section{PUBLISHER STATEMENT}

This work is made available according to the conditions of the Creative Commons Attribution-NonCommercialNoDerivatives 4.0 International (CC BY-NC-ND 4.0) licence. Full details of this licence are available at: https://creativecommons.org/licenses/by-nc-nd/4.0/

\section{LICENCE}

CC BY-NC-ND 4.0

\section{REPOSITORY RECORD}

Wang, Jinling, Shengkui Zeng, Vadim V. Silberschmidt, and Jianbin Guo. 2019. "Multiphysics Modeling Approach for Micro Electro-thermo-mechanical Actuator: Failure Mechanisms Coupled Analysis". figshare. https://hdl.handle.net/2134/25630. 


\title{
Multiphysics modeling approach for micro electro-thermo- mechanical actuator: Failure mechanisms coupled analysis
}

\author{
Jinling Wang ${ }^{\mathrm{a}, \mathrm{b}}$, Shengkui Zeng ${ }^{\mathrm{a}, \mathrm{c}}$, Vadim V. Silberschmidt ${ }^{\mathrm{b}}$, Jianbin Guo ${ }^{\mathrm{a}, \mathrm{c}, *}$ \\ ${ }^{a}$ School of Reliability and Systems Engineering, Beihang University, Beijing 100191, China \\ ${ }^{\mathrm{b}}$ Wolfson School of Mechanical and Manufacturing Engineering, Loughborough University, Leicestershire LE11 3TU, UK \\ ' Science and Technology on Reliability and Environmental Engineering Laboratory, Beijing 100191, China
}

\author{
A B S T R A C T
}

\begin{abstract}
The lifetime of micro electro-thermo-mechanical actuators with complex electro-thermo-mechanical coupling mechanisms can be decreased significantly due to unexpected failure events. Even more serious is the fact that various failures are tightly coupled due to micro-size and multi-physics effects. Interrelation between performance and potential failures should be established to predict reliability of actuators and improve their design. Thus, a multiphysics modeling approach is proposed to evaluate such interactive effects of failure mechanisms on actuators, where potential failures are pre-analyzed via FMMEA (Failure Modes, Mechanisms, and Effects Analysis) tool for guiding the electro-thermo-mechanical-reliability modeling process. Peak values of temperature, thermal stresses/strains and tip deflection are estimated as indicators for various failure modes and factors (e.g. residual stresses, thermal fatigue, electrical overstress, plastic deformation and parameter variations). Compared with analytical solutions and experimental data, the obtained simulation results were found suitable for coupled performance and reliability analysis of micro actuators and assessment of their design.
\end{abstract}

Keywords:

$\mu \mathrm{ETMA}$

Multiphysics modeling

FMMEA

Coupled failure mechanisms

\section{Introduction}

A micro electro-thermo-mechanical actuator ( $\mu$ ETMA) is one of key components in MEMS devices that are known for its advantages, such as low operation voltage, simple fabrication process and CMOS compatibility. Accordingly it has many applications, for instance in optical scanners, optical switches, micro-relays, etc. [1]. Based on different thermal expansions of two narrow "hot" arms and a wider "cold" arm, mechanical deflection of the actuator tip happens. Design of such a device is complicated by the fact that several physical phenomena are strongly coupled in the micro scale. Hence, designer's experience and intuition must be supplemented with multiphysics fields-coupled analysis.

Several research studies were conducted in the area of multiphysics design and analysis of $\mu$ ETMA. Colin illustrated a manufacture process and testing structure for better design in literature [2]. Zhu also employed an experimental approach to demonstrate the

\footnotetext{
* Corresponding author at: Science and Technology on Reliability and Environmental Engineering Laboratory, Beijing 100191, China. Tel.: +86 01082313839; fax: +8601082317663 .

E-mail address: guojianbin@buaa.edu.cn (J. Guo).
}

device performance and optimize its design [3]. Wilson tried to introduce new materials into micro sensors and actuators [4]. Additionally, more researchers were interested in modeling method to obtain practical information before fabrication. Huang [5], Jiang [6,7] and Yan [8] and others explained an analytical model to provide an insight into operation of actuators, and to predict their performance with new designs. Those studies have concentrated on performance-improving design and manufacture of $\mu$ ETMA, ignoring their reliability/failure matters. However, various unexpected failures under complicated thermo-electromechanical coupling mechanism and micro-size effects would greatly decrease its lifetime. Thus, failure mechanisms-incorporated assessment becomes an issue of critical importance for improvement of such devices used in critical applications and acceleration of their industrial uptake.

In recent years increasing attempts were undertaken to study failure behaviors of micro actuators by two ways. The first was the statistical approach based on experimental measurements of many devices. Standardized testing of actuators was partially covered in the Society of Automotive Engineers and Military via SAE J1221, SAE J575G and Military standard 750 [9]. Besides, at Sandia National Laboratories a special testing vehicle was 
developed which was capable of providing failure test [10]. In order to assess the reliability under desired environmental and operational conditions, comprehensive humidity and temperature reliability tests were also implemented in [11]. And literatures $[1,12,13]$ explained some typical failure mechanisms (such as friction, wear and fatigue), and their testing methods. Such experimental approaches resulted in some common disadvantages, including increased cost, required time and effort. So quite a few researchers tended to the second one based on modeling approach which could provide deeper study from the point of physical mechanism with better efficiency and less expense. Muratet [14] and Matmat [15] built a "virtual prototype" using VHDL-AMS language, aiming at estimating reliability of micro actuators based on failure data. Melle introduced a reliability modeling method to describe the dielectric charging kinetic [16]. In [17-21] typical structure failure phenomena, such as creep, fatigue and delamination of micro actuators, was analyzed based on Finite Element Method (FEM). However, physical modeling method regarding failure matters was still in its infancy stage. As well known, failure behaviors in $\mu$ ETMAs are more complicated because of their tiny scale, layered inhomogeneity and coupling of fields from different physical origins. A systematic failure analysis about $\mu$ ETMA has yet to be done, studying their failure mechanisms, modes, potential causes and effects. And understanding the coupled influence of various failure mechanisms on performance of actuators is also necessary for reliable product design.

To overcome these limitations, a failure mechanisms-coupled multiphysics modeling approach is proposed to study $\mu$ ETMA's performance, reliability and links between them. To obtain systematic failure information, FMMEA (Failure Modes, Mechanisms, and Effects Analysis) tool is employed, taking its advantages of discovering possible failure modes and design weakness from fabrication to operation. It concludes that residual stresses, creep/yielding/plastic deformation of nickel layer, electrical overstress, thermal fatigue, parameter variations, etc. play a significant role on reliability of micro actuators. Then the ways to incorporate these failure behaviors into functional model of $\mu$ ETMA are studied in the platform of COMSOL and MATLAB. Failure mechanisms-coupled analysis is finally implemented to provide recommendations for better device design before its practical fabrication.

\section{Working principle of $\mu$ ETMA}

Compared with electrostatic actuation, electro-thermal one offers high forces and large deflections, leading to lower contact resistances, reduced risk of stiction and better open-contact isolation. In combination with the use of a clamping mechanism to reduce the power consumption, these devices are well suited for stationary application. In this research a MEMSCAP DC switch (shown in Fig. 1(a)) is studied for failure mechanisms coupled analysis.

It is bi-stable and consumes no power in either ON or OFF position [22]. The switch is fabricated in the "open" position, and in order to close the switch, an appropriate switching sequence, i.e. heating sequence of the two actuators is performed (shown in Fig. 1(b)).

In an individual actuator, the key part is the U-shaped structure ("heatuator") containing two thin "hot" beams and a wide "cold" beam (shown in Fig. 1(c)). The "cold" beam, which is used to carry the electrical signal, is electrically isolated from "hot" beams, actuating the switch. Different thermal expansions are used to achieve motion along the wafer surface. Its working principle can be described in the following way: $U \rightarrow I \rightarrow Q \rightarrow \Delta T \rightarrow S \rightarrow \sigma \rightarrow D$. When voltage $U$ is applied to the terminal anchor, current $I$ flows

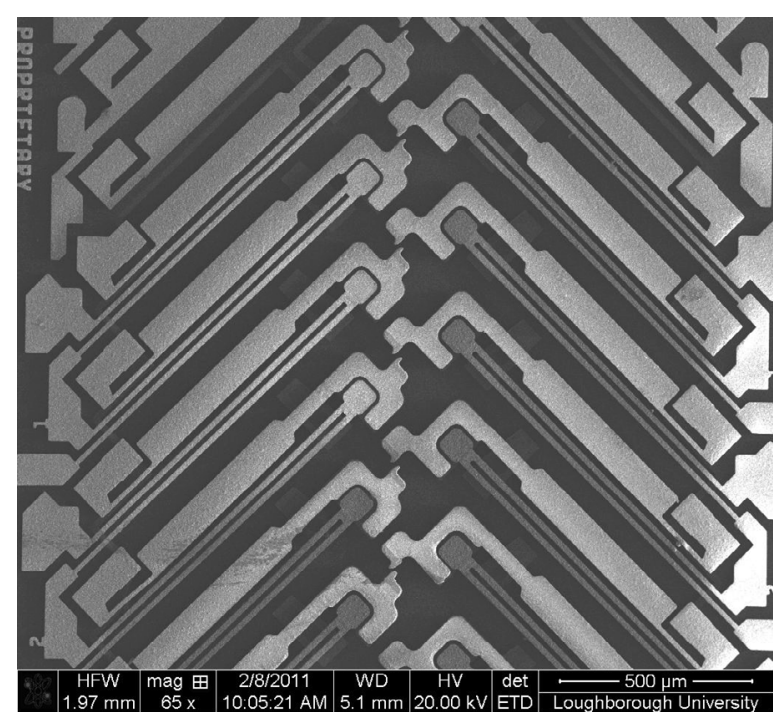

(a)
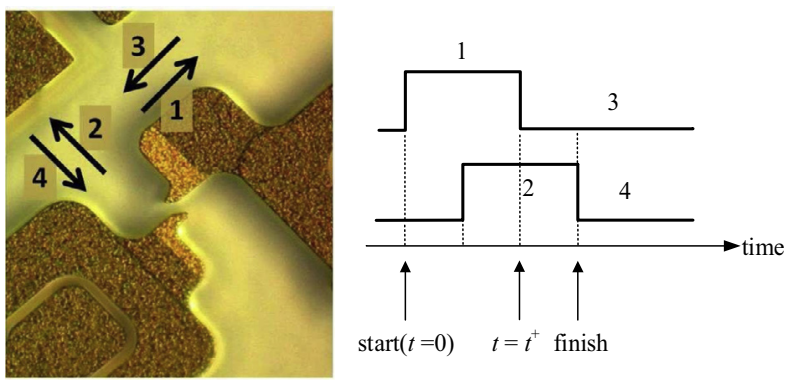

(b)

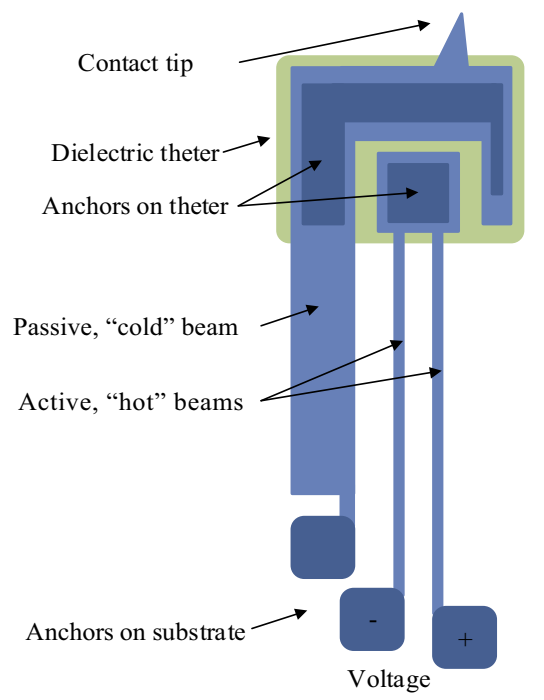

(c)

Fig. 1. $\mu E T M A$ : (a) Assembly in MEMS devices; (b) Latching sequence of the actuator; (c) It includes a passive beam carrying the electrical information ("cold" beam), two active beams for actuation ("hot" beams), a dielectric theter between the passive and active beam, a contact tip and some anchors [20].

through the two "hot" beams. Joule heat $Q$ in the two beams leads to thermal stress $S$, expansion $\sigma$ and ultimately mechanical deflection $D$. Detailed electro-thermo-mechanical analysis is given below. 


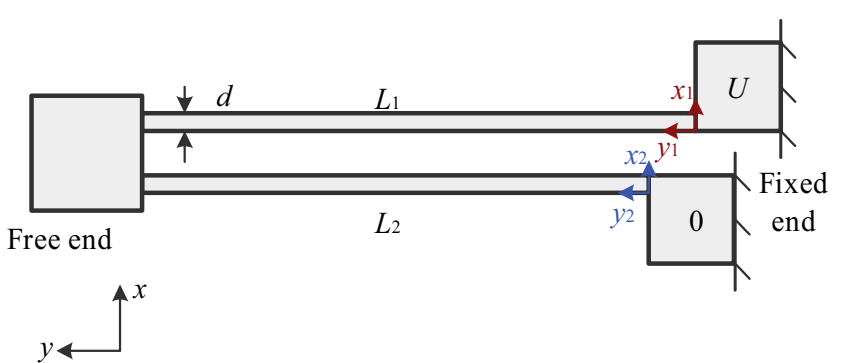

Fig. 2. Cross section of the $\mu$ ETMA's "hot" beams.

\subsection{Electro-thermal analysis}

Fig. 2 shows the simplified geometry of the $\mu$ ETMA's "hot" beams. $L_{1}$ is the length of one of "hot" beams and $L_{2}$ is that of the other. Assuming that each cantilever has the same width $d$ and thickness $b$, and they are uniform along their lengths and widths. For fast computation, local coordinate systems $\left(x_{1}, y_{1}\right)$ and $\left(x_{2}, y_{2}\right)$ are employed.

When the heating layer is powered, the temperature along the cantilever goes up due to Joule heating and "hot" arms will elongate. For simplicity, it is assumed that:

(a) The layer thickness satisfies $d \leqslant b \ll L_{1}, L_{2}$, therefore, thickness and width effects are ignored. Temperature distribution along the $\mu$ ETMA's thickness and width direction can be assumed uniform.

(b) There is no thermal resistance and peeling effect between any two adjacent layers.

(c) The electrical/thermal physical parameters of film materials are constants, and coupling between the electrical and temperature field is neglected.

(d) The distribution of electrical field along the material surface is uniform.

(e) Radiative heat transfer is negligible.

According to literatures [6,7,25-28], based on the law of conservation of energy, Fourier's laws and Joule's laws, the temperature variation of the face sheet with respect to time and position when driving the $\mu$ ETMA is:

$\rho C_{p} \frac{\partial T(x, y, t)}{\partial t}=k \nabla^{2} T(x, y, t)-\frac{2 h}{b} T(x, y, t)+\frac{U^{2}}{\left(L_{1}+L_{2}\right)^{2} \Omega_{0}}$

where $\rho$ is the density of materials, $C_{p}$ is heat capacity at constant pressure, $h$ is the coefficient of heat transfer, $\Omega_{0}$ is the reference resistivity, $U$ is the applied voltage, $k$ is thermal conductivity, and $T(x, y, t)$ is the temperature difference between "hot" beam and substrate. $t$ is short for latching the switch (shown in Fig. 1(b)). And both beam $L_{1}$ and $L_{2}$ utilize the same material.

The entire beam is initially at the ambient temperature before heating. The fixed end of the cantilevers is anchored to the substrate and the free end is attached to the "cold" beam by insulator. Both free and fixed ends remain at ambient temperature, $T_{0}=25^{\circ} \mathrm{C}$, Type I. So the initial and boundary conditions are:

$\left.T(x, y, t)\right|_{t=0}=T(x, y, 0)=0$

$\left.T(x, y, t)\right|_{y=0}=\left.T(x, y, t)\right|_{y=L}=0$

Now the temperature difference between "hot" beam and ambient can be obtained by simultaneously solving Eq. (1), initial and boundary conditions Eqs. (2) and (3) [25,27]:

$$
\begin{aligned}
T(x, y, t) \approx & T_{0} \frac{2 \bar{P}}{\pi} \sum_{m=1}^{\infty} \frac{\mu^{2}}{(2 m-1)\left[(2 m-1)^{2} \pi^{2}+\mu^{2}\right]} \\
& \times \sin \frac{(2 m-1) \pi y}{L}\left\{1-e^{-\left[\mu^{2}+(2 m-1)^{2} \pi^{2}\right](d / L)^{2} t / \tau}\right\}
\end{aligned}
$$

where $\bar{P}=U^{2} d /\left(L^{2} \Omega_{0} h T_{0}\right) ; \tau=\rho C_{P} d / 2 h ; \mu=(L / d) \sqrt{2 B i}$ with $B i \equiv h d /$ $k$, the Biot number.

When Eqs. (1)-(4) is used to solve the temperature distribution of $L_{1}$ and $L_{2}$, the local coordinate systems $(x, y)$ should change to $\left(x_{1}, y_{1}\right)$ and $\left(x_{2}, y_{2}\right)$, the length $L$ change to $L_{1}$ and $L_{2}$, respectively. And this solution Eq. (4) is suitable for those cases that material properties are independent with temperature $T$. In other case, the solution depends on the coupling function with $T$. At $t=t^{+}$, the applied voltage is switched off and cooling begins.

\subsection{Thermo-mechanical analysis}

The motion in the studied device is typically generated by amplification of thermal expansion. A small amount of thermal expansion translates to a large deflection of the overall device. A higher current density in the "hot" beam causes its large temperature and subsequently larger expansion than that of "cold" beam, thus producing lateral arcing motion toward the "cold" beam. The deformed shape of "hot" beams is illustrated in Fig. 3.

In light of the assumption $d \leqslant b \ll L_{1}, L_{2}$, we can consequently make another assumption that the thickness of the $\mu$ ETMA is also much less than its curvature radius, which is important for the thermal-elastic analysis [23]. The resultant temperature distribution can then be used to obtain the thermal stress and expansion strain. Finally, with the elastic equation the stresses in the device can also be achieved. The total stain is given by

$\varepsilon=\varepsilon^{m l}+\varepsilon^{\text {th }}$

where $\varepsilon^{e l}$ is the mechanical strain, and $\varepsilon^{\text {th }}$ is the thermal strain which is given by

$\varepsilon^{\text {th }}=\alpha T$

where $\alpha$ is the coefficient of thermal expansion. Residual stresses are not included in this model as they depend on the processing technique.

\subsection{Kinematics of tip deflection}

In this case, given that tip deflection is small compared with the length of arms, the structure is elastic and homogenous, and the $\mu$ ETMA arm is narrow enough. So strain along the width can be neglected in comparison with that along the length. A geometric deformation pattern and angular relationship of both cantilevers of the "hot" arm is shown as Fig. 4.

Assuming that curvatures of both cantilevers are very small and characterized by respective radius $R_{1}$ and $R_{2}$, they can be determined as $[7,24]$ :

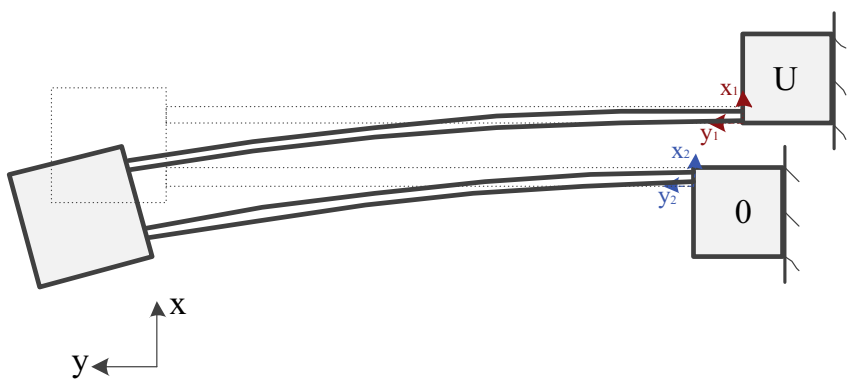

Fig. 3. Deformed shape of two "hot" arms. 


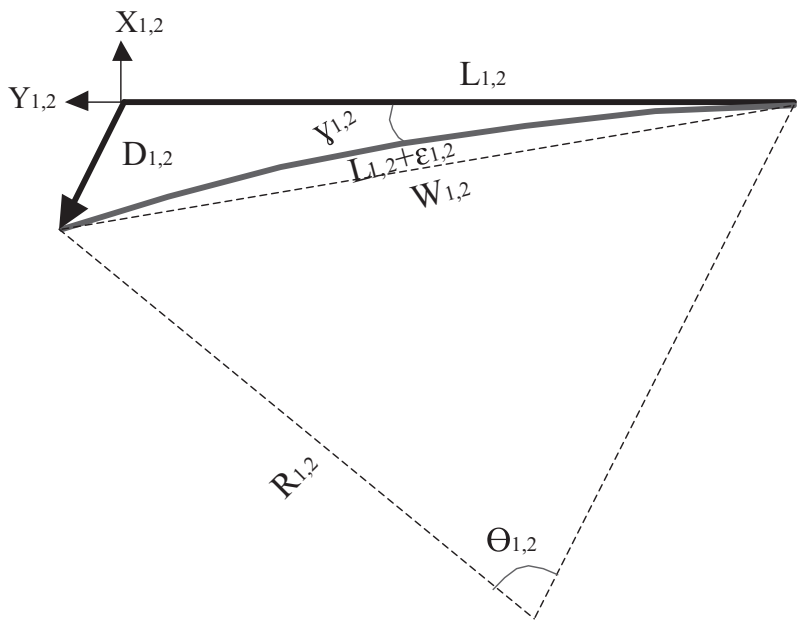

Fig. 4. Geometric relationship of both "hot" cantilevers.

$R_{i}=\frac{\alpha T_{i}\left(x_{i}, y_{i}\right) d / 2}{E I}, \quad i=1,2$

where $T_{i}(i=1,2)$ can be calculated using Eq. (4), and EI is flexural rigidity.

So the central angles are expressed as:

$\theta_{i}=\frac{L_{i}+\varepsilon_{i}}{R_{i}}, \quad i=1,2$

where $\varepsilon_{i}, i=1,2$ are defined by Eqs. (5) and (6).

Tip deflection $D_{i}, i=1,2$ can be calculated using triangular relationships in Fig. 4.

\section{FMMEA approach to characterize $\mu$ ETMA's failure mechanisms}

In contrast to macro-electromechanical system, the analyzed $\mu$ ETMA has inherently many different failure mechanisms and modes due to micro size effect, related to variations in fabrication, packaging, operation processes and environment; for example, interface delamination because of stress concentration gradient between different tiny material layers, stiction due to presence of capillary condense, residual stresses caused by micro-welding, particle contamination as a result of die singulation and handling, etc. Additionally, an importance reason for failures of $\mu$ ETMA exists in multiple domains of energy (electro, thermo and mechanical); for instance, residual stresses due to temperature gradient, contact resistant degradation because of thermal cycling, and melt of hot arms caused by electrical overstress, etc. Some of them will eventually cause catastrophic results or malfunctioning. Therefore, it is necessary to investigate reliability of the $\mu$ ETMA in a holistic way. An established reliability analysis tool, FMMEA (Failure Modes, Mechanisms, and Effects Analysis) provides a systematic and structured study of potential failures that might occur in any part of a system; it can be used to determine their potential effects on system reliability to improve the design, manufacturing process and operation [13]. This analysis is proactive since problems can be investigated before completion of design, preventing in-service failures. Thus the FMMEA tool is employed to specific effects and failure mechanisms linking to observed failure modes.

A detailed FMMEA form for the $\mu$ ETMA is given in Table 1 [2931]. The FMMEA outcomes can be summarized in the following way: (a) Technology- and design-related issues (including fabrication, packaging and assembly processes): residual stresses are one of major failure modes either during fabrication or packaging and assembly processes, and induce deformation in service with aging. Excessive residual stresses can warp the actuator and bind it against the substrate, causing its failure. A breakdown due to over etching is a severe manufacturing fault, which can directly result in a failed device. In addition, deviations of geometric, electrical, thermal and mechanical parameters are also unavoidable in the above processes, affecting considerably the performance of the actuator. Improving fabrication, assembly and packaging processes would allow achieving design parameters, minimizing residual stresses and reducing the probability of failures, and currently more efforts are applied in this area.

(b) Operation-related issues: As the thermal actuator is heated to high temperature during its operation, stresses and strains in "hot" arms increase. A conductive material at the hottest region is prone to creep, yielding even plastic failure, where plastic deformation will emerge. Another problem that should be taken seriously is overdriving the actuator that can cause melting and redistribution of "hot" arms until arms thin out enough to burn through. It makes "hot" arms shorter, causing the overall actuator to deflect further away from its initial position after the input power is removed. Material and structure parameters of arms will also change with bending. Such non-reversible deformation can drastically shorten the lifetime of the actuator, but they can be diminished by designing a wider "hot" arm or selecting other material to resist higher temperature. Other failure modes, such as thermal fatigue causing by cyclic long-term loading can degrade electro-thermo-mechanical properties, and even result in variation of microstructure (grain sizes, grain boundaries), accelerated growth of micro or nanoflaws in structure and eventually interface delamination and fracture. Contact resistance degradation failure happens at the gold tip of $\mu$ ETMA, causing abrupt resistance to block connection of the switch.

(c) Environment-related issues: This MEMS device is sensitive to environmental factors, such as vibration, humidity and temperature.

Due to effects of micro size and multi-physics fields, unavoidably such failure mechanisms would be tightly coupled with each other; for instance, plastic deformation of materials will decrease fatigue life by introducing unrecoverable strain; conversely thermal cycling will also accumulate creep and plastic deformations until fracture. Thus, only multiple failures occurring at the same time (or after some small time shift) normally represent systems susceptibility to potential loss of function. Failure mechanisms coupled analysis deserves an indepth discuss in the future by the proposed approach of multiphysics modeling.

\section{Multiphysics modeling of failure mechanisms}

Previous studies have illustrated that electro-thermo-mechanical multiphysics and failure mechanisms-coupled effects should be properly taken into account to predict reliability of $\mu$ ETMA. Hence, a dedicated simulation procedure involving a multiphysics FE-model, failure models and special interfaces between them is developed within the platform of COMSOL Multiphysics ${ }^{\circledR}$ and Matlab (shown in Fig. 5).

Firstly, the device structure requires a full 3D modeling of the geometry in order to achieve adequate results. COMSOL Multiphysics ${ }^{\circledR}$ is a suitable tool to simulate electro-thermo-mechanical 
Table 1

FMMEA for $\mu$ ETMA.

\begin{tabular}{|c|c|c|c|c|c|c|}
\hline Process & Potential failure mechanism & Potential failure mode & Potential failure cause & OCC & SEV & RPN \\
\hline \multirow[t]{14}{*}{ Fabrication } & \multirow[t]{5}{*}{ Stiction } & \multirow[t]{3}{*}{ 1. Actuator adhesion to substrate } & 1. Presence of capillary condense & \multirow[t]{5}{*}{4} & \multirow[t]{5}{*}{6} & \multirow[t]{5}{*}{24} \\
\hline & & & 2. Left over oxides and residues & & & \\
\hline & & & 3. Humidity caused by capillary forces & & & \\
\hline & & 2. Failed device & 3. Residual stresses induced deformation & & & \\
\hline & & & $\begin{array}{l}\text { 4. Improper release due to inadequate } \\
\text { release etch }\end{array}$ & & & \\
\hline & \multirow[t]{3}{*}{ Residual stress } & 1. Unwanted deformation & 1. Temperature gradient & \multirow[t]{3}{*}{6} & \multirow[t]{3}{*}{5} & \multirow[t]{3}{*}{30} \\
\hline & & $\begin{array}{l}\text { 2. Warping or bonding of structure } \\
\text { against substrate }\end{array}$ & 2. Micro welding & & & \\
\hline & & & $\begin{array}{l}\text { 3. Deposition of different thin-film } \\
\text { materials }\end{array}$ & & & \\
\hline & \multirow[t]{2}{*}{ Particle contamination } & $\begin{array}{l}\text { 1. Degradation of electro-thermo- } \\
\text { mechanical properties }\end{array}$ & 1. Fabrication contamination & \multirow[t]{2}{*}{3} & \multirow[t]{2}{*}{2} & \multirow[t]{2}{*}{6} \\
\hline & & 2. Obstruct output displacement/force & & & & \\
\hline & Break & 1. Failed device & 1. Over etching & 1 & 9 & 9 \\
\hline & \multirow[t]{3}{*}{ Geometric and material variations } & $\begin{array}{l}\text { 1. Unpredictable performance and } \\
\text { lifetime }\end{array}$ & 1. Process instability & \multirow[t]{3}{*}{7} & \multirow[t]{3}{*}{2} & \multirow[t]{3}{*}{14} \\
\hline & & & $\begin{array}{l}\text { 2. Over/under etching, etching time, } \\
\text { etchant concentrations }\end{array}$ & & & \\
\hline & & & $\begin{array}{l}\text { 3. Light quality of mask resolution } \\
\text { exposure }\end{array}$ & & & \\
\hline \multirow{7}{*}{$\begin{array}{l}\text { Packaging and } \\
\text { assembly }\end{array}$} & \multirow[t]{2}{*}{ Residual stress } & 1. Package warpage or bowing & 1. Thermal cycling due to ambience & \multirow[t]{2}{*}{4} & \multirow[t]{2}{*}{6} & 24 \\
\hline & & 2. Delamination in presence of moisture & $\begin{array}{l}\text { 2. Die attach, lid sealing, wafer level } \\
\text { bonding, molding }\end{array}$ & & & \\
\hline & Particle contamination & 1. Change of properties & 1. Die singulation, handling & 3 & 2 & 6 \\
\hline & & 2. Electrical shorts & & & & \\
\hline & Outgassing & 1. Increase of thermal loss & 1. Packaging & 2 & 3 & 4 \\
\hline & & 2. Oxidation & & & & \\
\hline & & 3. Complex chemical vapors & & & & \\
\hline Operation & Corrosion & $\begin{array}{l}\text { 1. Degradation of electrical and } \\
\text { mechanical parameters }\end{array}$ & 1. Presence of water or other fluid & 2 & 3 & 6 \\
\hline & Oxidation & 1. Degradation of structural material & 1. Presence of humidity & 2 & 3 & 6 \\
\hline & Metal creep & $\begin{array}{l}\text { 1. Excessive plastic deformation even } \\
\text { fracture }\end{array}$ & 1. High stress and high temperature & 7 & 4 & 28 \\
\hline & & & 2. Long-term service & & & \\
\hline & & & 3. Creep-sensitive metal & & & \\
\hline & Yielding & 1. Accelerated buckling & 1. High stress and temperature & 6 & 5 & 30 \\
\hline & Plastic hardening & 1. Bucking and back bending & $\begin{array}{l}\text { 1. Thermally induced changes in material } \\
\text { properties }\end{array}$ & 5 & 7 & 35 \\
\hline & & $\begin{array}{l}\text { 2. Material in hot arm melts and } \\
\text { redistributes }\end{array}$ & & & & \\
\hline & & $\begin{array}{l}\text { 3. Offset in rest position and decreased } \\
\text { output }\end{array}$ & & & & \\
\hline & & 4. Failed devices & & & & \\
\hline & Fracture & 1. Failed devices & 1. Over electrical stress & 1 & 9 & 9 \\
\hline & & & 2. Micro-nano defects (Voids, Cracks) & & & \\
\hline & Interface delamination & 1. Losing adhesion to substrate & $\begin{array}{l}\text { 1. Stress gradient between different } \\
\text { materials }\end{array}$ & 6 & 6 & 36 \\
\hline & & & 2. Micro-nano defects(Voids, Cracks) & & & \\
\hline & Electrical overstress & $\begin{array}{l}\text { 1. Hot arm melts, redistributes, } \\
\text { evaporates and burns through } \\
\text { 2. Failed devices }\end{array}$ & 1. Input of excessive power & 2 & 8 & 16 \\
\hline & Dielectric charging & 1. Stiction & 1. Electrostatic force & 3 & 4 & 12 \\
\hline & $\begin{array}{l}\text { Structural short (electrical and non- } \\
\text { electrical connection) }\end{array}$ & 1. Change in electrical parameters & 1. Wear particles & 3 & 7 & 21 \\
\hline & & 2. Failed devices & 2. Lorenz forces & & & \\
\hline & Wear/friction & 1. Shift of electrical parameters & $\begin{array}{l}\text { 1. Sliding rough surfaces in contact } \\
\text { 2. Adhesion }\end{array}$ & 4 & 4 & 16 \\
\hline & & 2. Contact resistance shifts & 3. Surface fatigue & & & \\
\hline & Whisker formation & $\begin{array}{l}\text { 1. Possible increase of charging } \\
\text { sensitivity }\end{array}$ & $\begin{array}{l}\text { 1. High compressive stress in metal } \\
\text { resulting in grains extrusions }\end{array}$ & 2 & 3 & 6 \\
\hline & & & 2. Might be enhanced by T-steps of input & & & \\
\hline & Thermal fatigue & 1. Fracture & $\begin{array}{l}\text { 1. Large local stress variations due to } \\
\text { motion of parts }\end{array}$ & 6 & 7 & 42 \\
\hline & & 2. Degradation of performance & $\begin{array}{l}\text { 2. Enhanced probability if cracks are } \\
\text { present }\end{array}$ & & & \\
\hline & & 3. Delamination & 3. Surfaces are rough & & & \\
\hline & Contact degradation & $\begin{array}{l}\text { 1. Cannot satisfy performance } \\
\text { requirement }\end{array}$ & $\begin{array}{l}\text { 1. Thermal induced degradation of } \\
\text { material parameters }\end{array}$ & 5 & 6 & 30 \\
\hline
\end{tabular}


Table 1 (continued)

\begin{tabular}{|c|c|c|c|c|c|c|}
\hline Process & Potential failure mechanism & Potential failure mode & Potential failure cause & OCC & SEV & RPN \\
\hline \multirow{5}{*}{$\begin{array}{l}\text { Environment } \\
\text { factors }\end{array}$} & Stiction & 1. Fracture & 1. Shock and vibration & 3 & 3 & 9 \\
\hline & & & 2. Humidity & & & \\
\hline & Oxidation & 1. Fracture & 1. Humidity & 3 & 3 & 9 \\
\hline & $\begin{array}{l}\text { Thermomechanical deformation } \\
\text { stiction }\end{array}$ & 1. Degradation of performance & 1. Temperature & 4 & 4 & 16 \\
\hline & & 2. Fracture & & & & \\
\hline
\end{tabular}

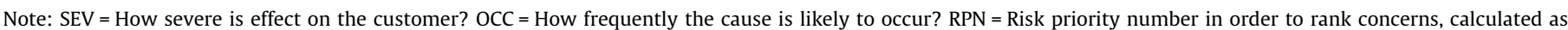
$\mathrm{SEV} \times \mathrm{OCC}$.

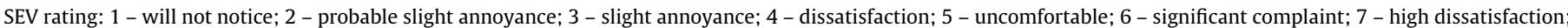
8 - very high dissatisfaction; 9 - endangered with warning; 10 - endangered without warning.

OCC rating: $1-1$ in $1,000,000 ; 2-1$ in 20,$000 ; 3-1$ in $5000 ; 4-1$ in $2000 ; 5-1$ in $500 ; 6-1$ in $100 ; 7-1$ in $50 ; 8-1$ in 20 ; $9-1$ in 10 .

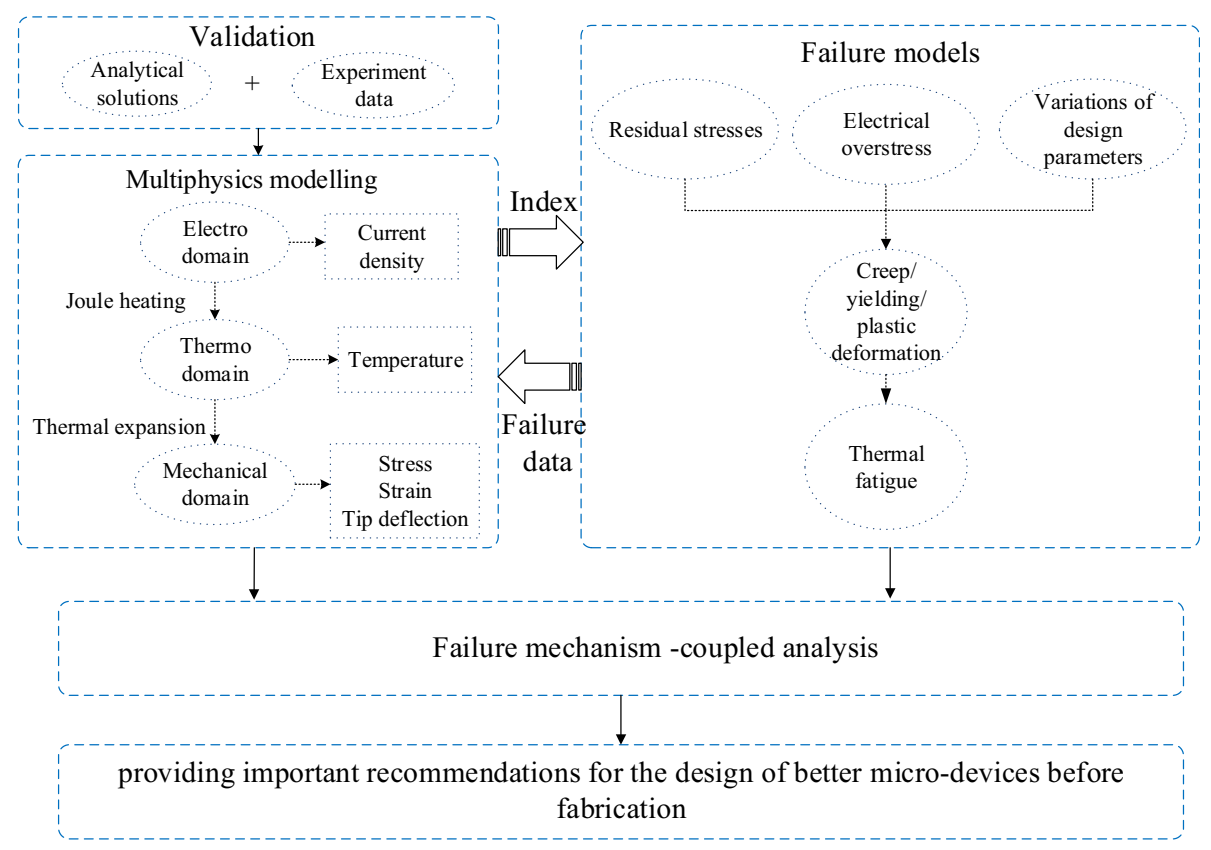

Fig. 5. Coupling of electrical-thermal-mechanical-reliability multiphysics domains.

behaviors with Joule heating and thermal expansion module in 3D. Comparison with validated analytical solutions and experimental data could help to verify the reasonability of the 3D simulation. The most critical and difficult part of the suggested approach exists in incorporating failure mechanisms and their coupling into the multiphysics model, and monitoring their effects on performance of $\mu$ ETMA by means of user subroutine in MatLab. Interacting with changed geometries, materials, boundary conditions and study solver according to various failure behaviors, 3D model could represent the operation of practical devices. On this basis failure mechanismcoupled multiphysics analysis can be finally implemented to provide important recommendations for the design and manufacturing of better devices before fabrication.

\subsection{Geometrical structure and material properties}

A simplified numerical model of the $\mu$ ETMA was used in the POLYNOE Programme [22] to reduce the number of nodes in the mesh and thus improve simulation efficiency. Various critical dimensions of the actuator are shown in Fig. 6 and relevant geometrical parameters are given in Table 2 . The numerical model allowed the account for the structure in great details.

Metal multi-user MEMS processes (MetalMUMPs) provide a procedure for constructing and packaging $\mu$ ETMA devices [22].
The material part in these researches is composed of two layers, electroplated nickel and substrate silicon. Some of them are temperature-dependent, e.g. the Young's modulus $E$, coefficient of thermal expansion $\alpha$, electrical conductivity $\sigma$ and thermal conductivity $k$ for nickel. They are described by the following relationships:

$$
\begin{aligned}
& E(T)=230 \cdot(1-0.000286 T) \\
& \alpha(T)=3.725 \cdot\left(1-e^{-0.00588(T-125)}\right)+0.00548 T \\
& \sigma(T)=50000 /\left[1+0.00125 \cdot\left(T-T_{0}\right)\right] \\
& k(T)=10^{8} /\left(-2.2 \cdot T^{3}+9000 T^{2}-10^{6} T+14\right)
\end{aligned}
$$

All other material properties are summarized in Table 3, where $v$ is the Poisson's ratio, $C_{p}$ is heat capacity at constant pressure, $\Omega_{0}$ is reference resistivity, $\rho$ is density of materials and $h$ is the coefficient of heat transfer [18-20,32,33].

\subsection{Realization of failure modes in modeling}

As indicated in outcomes of FMMEA, typical failure modes observed in the $\mu$ ETMA and their packages include residual stresses, thermal fatigue, electrical overheating, creep/yielding/plastic 


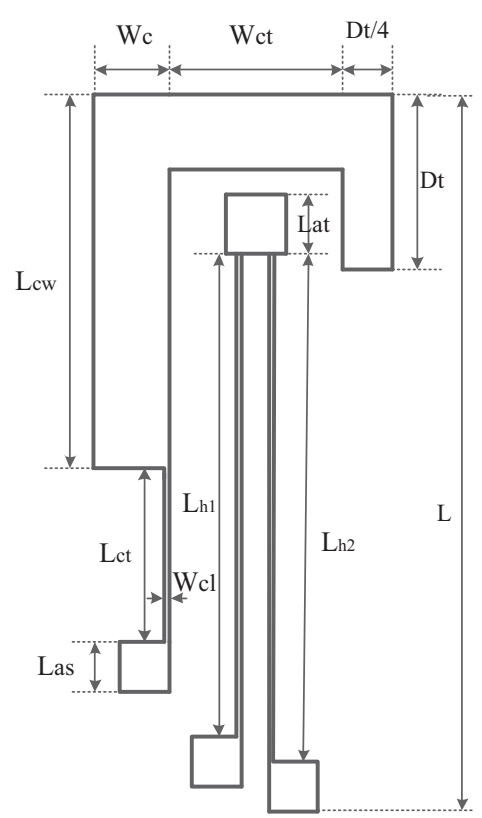

Fig. 6. Simplified structure of the $\mu$ ETMA.

deformation, parameter variations and contact resistance degradation. The latter happens between the golden tips of two connected actuators that are not included in this research. Other failure factors are summarized as below:

\subsubsection{Residual stresses}

In the MEMSCAP MetalMUMPs process, thin films are deposited at elevated temperatures, followed by cooling to room temperature. As a result, they are subjected to residual stresses which may cause bending of the structure. Such bending can lead to failure as described above. An understanding of correlation between residual stresses, bending of such thin films and performance of actuators is therefore essential for prevention of such technological-related failures.

Originating from a temperature change and a mismatch in the coefficients of thermal expansion, the residual stresses could be treated as pre-stress in the substrate and the metal layer. An assumption is made that they are constant in each layer (i.e. there is no strain gradient through thickness) [34]. For the silicon layer the typical value of residual stresses is $50 \mathrm{MPa}$ (compressive) [24]. In the metal layer they depend greatly on process parameters

Table 2

Geometrical parameters in FE-model.

\begin{tabular}{|c|c|c|}
\hline Description & Symbol & $\begin{array}{l}\text { Magnitude } \\
(\mu \mathrm{m})\end{array}$ \\
\hline Length of the whole component & $L$ & 2400 \\
\hline Length of wide part of "cold" arm & $L_{c w}$ & 1300 \\
\hline Length of thin part of "cold" arm & $L_{c t}$ & 200 \\
\hline Length of anchor on substrate & $L_{a s}$ & 200 \\
\hline Length of anchor on theater & $L_{a t}$ & 160 \\
\hline Width of wide part of "cold" arm & $W_{c}$ & $L_{a s}$ \\
\hline Width of middle part of theater & $W_{c t}$ & $W_{c}+50$ \\
\hline Width of thin part of "cold" and "hot" arms & $W_{c l}$ & $L_{a s} / 10$ \\
\hline Length of dielectric theter & $D_{t}$ & 400 \\
\hline Length of short "hot" arm & $L_{h 1}$ & 1350 \\
\hline Length of long "hot" arm & $L_{h 2}$ & $L_{h 1}+L_{a s} / 2$ \\
\hline $\begin{array}{l}\text { Gap between theter and upper end of anchor on } \\
\text { theter }\end{array}$ & $\operatorname{gap}_{1}$ & $\begin{array}{l}\left(W_{c t}-L_{a t}\right) / \\
2+L_{a t} / 3\end{array}$ \\
\hline $\begin{array}{l}\text { Gap between theter and left end of anchor on } \\
\text { theter }\end{array}$ & $\operatorname{gap}_{2}$ & $L_{a t} / 3$ \\
\hline Thickness of the actuator & $T_{h}$ & 20 \\
\hline
\end{tabular}

such as the deposition temperature, metal-layer thickness, substrate temperature. The value used in the modeling is $10 \mathrm{MPa}$ (tensile). A more exact value can be determined by measuring test structures manufactured with the same process as the arms. The result section shows the deflection distribution resulted from residual stresses.

\subsubsection{Thermal fatigue}

Since in service the power is repeatedly switched on and off, the component is subjected to thermal cycling. These thermal and mechanical cycles and their coupling result in variation of grain size (thanks to annealing in hottest regions), grain boundaries, surface roughness and accelerate growth of micro and nano-flaws in the structure. This cyclic loading causes the progressive and localized structural damage, due to fatigue. Modeling this kind of fatigue failure is realized in two ways: assessing fatigue properties of the studied material and degradation of electro-thermo-mechanical properties.

To estimate the thermal fatigue life of "hot" arms, the strainbased fatigue properties are used in the Coffin-Manson relationship $[20,35]$.

$\frac{\Delta \varepsilon^{p l}}{2}=\varepsilon\left(2 N_{f}\right)^{c}$

where $\Delta \varepsilon^{p l}$ is the plastic strain amplitude, $c$ is known as the fatigue ductility exponent that, in general, varies from -0.5 to $-0.7, N_{f}$ is the fatigue life (in cycles) and $\varepsilon$ is the fatigue ductility coefficient.

\subsubsection{Electrical overstress}

As introduced in FMMEA, higher stresses and damage are generated in over-driven actuators. That can result in melting and redistribution of nickel, or creep/yielding/plastic deformation in the microstructure. Thus in modeling, higher working voltage is applied to the actuator study this failure mechanism by $10 \mathrm{~V}$ or more.

\subsubsection{Creep/yielding/plastic deformation}

Because of the long-term exposure to high levels of stress and the increased temperature, nickel layer at micro/nano scale can creep slowly or deform permanently beyond elastic range. Plastic mechanical properties of nickel are defined as yielding strength (367 MPa), tangent modulus (92 GPa) and the kinematic strain hardening rate $H(4 \mathrm{GPa}( \pm 2 \%))[20]$.

\subsubsection{Variations of design parameters}

Due to some manufacturing and operation reasons (including the effect of other failure mechanisms), critical dimensions of the actuator including the lengths $L_{h 1}$ and $L_{h 2}$, width $W_{c l}$ and thickness $T_{h}$ of "hot" arms and some other geometrical parameters can change and degrade from one run to other run. And within the same run, such variations exist from one chip to other chip. This will result in a drift of the actuator's performance, even soft failures. Regarding variations of material properties, the local values of the Young's modulus $E$, the coefficient of thermal expansion $\alpha$, electrical conductivity $\sigma$, etc. affect in a similar way. Seven different cases are designed and shown in Table 4. In this study the sensitivity factor is used to characterize the influence of the input geometrical parameters and material properties on the actuator's performance. It is defined as

$S=\frac{\Delta \delta}{\delta_{0}} / \frac{\Delta W}{W_{0}}$

This parameter characterizes the effect of parameters on the actuator, where $\delta_{0}$ is the performance related to $W_{0}$ and $\Delta \delta$ is the variation of this performance indexes caused by the variation $\Delta W$. 
Table 3

Electro, thermo and mechanical properties of the $\mu$ ETMA

\begin{tabular}{|c|c|c|c|c|c|c|c|c|c|}
\hline Material & $E(\mathrm{GPa})$ & $v$ & $\alpha\left({ }^{\circ} \mathrm{C}^{-1} \cdot 10^{-6}\right)$ & $C_{p}(\mathrm{~J} /(\mathrm{kg} \mathrm{K}))$ & $\sigma(\mathrm{S} / \mathrm{m})$ & $k(\mathrm{~W} /(\mathrm{m} \mathrm{K}))$ & $\Omega_{0}(\Omega \mathrm{m})$ & $\rho\left(\mathrm{kg} / \mathrm{m}^{3}\right)$ & $h\left(\mathrm{~W} / \mathrm{m}^{2} \mathrm{k}\right)$ \\
\hline Nickel & $E(T)$ & 0.31 & $\alpha(T)$ & 678 & $\sigma(T)$ & $k(T)$ & $2 e-5$ & 8900 & 20,000 \\
\hline Silicon & 130e9 & 0.28 & $3.1 \mathrm{e}-6$ & 700 & 1.7 & 130 & $\sim$ & 2329 & 400 \\
\hline
\end{tabular}

Table 4

Variations of geometrical and material parameters.

\begin{tabular}{|c|c|c|c|c|c|c|c|}
\hline Case & $E(\mathrm{GPa})$ & $\alpha\left({ }^{\circ} \mathrm{C}^{-1}\right)$ & $\sigma(\mathrm{S} / \mathrm{m})$ & $k(\mathrm{~W} /(\mathrm{m} \mathrm{K}))$ & $L_{h 1}(\mu \mathrm{m})$ & $W_{c l}(\mu \mathrm{m})$ & $T_{h}(\mu \mathrm{m})$ \\
\hline 1 & $\begin{array}{l}0.05 E, 0.1 E, 0.5 E \\
E, 2 E, 4 E\end{array}$ & Eq. (9) & Eq. (10) & Eq. (11) & 1350 & 20 & 20 \\
\hline 2 & Eq. (8) & $\begin{array}{l}0.05 \alpha, 0.1 \alpha, 0.5 \alpha \\
\alpha, 2 \alpha, 4 \alpha\end{array}$ & Eq. (10) & Eq. (11) & 1350 & 20 & 20 \\
\hline 3 & Eq. (8) & Eq. (9) & $\begin{array}{l}0.05 \sigma, 0.1 \sigma, 0.5 \sigma \\
\sigma, 2 \sigma, 4 \sigma\end{array}$ & Eq. (11) & 1350 & 20 & 20 \\
\hline 4 & Eq. (8) & Eq. (9) & Eq. (10) & $\begin{array}{l}0.05 k, 0.1 k, 0.5 k \\
k, 2 k, 4 k\end{array}$ & 1350 & 20 & 20 \\
\hline 5 & Eq. (8) & Eq. (9) & Eq. (10) & Eq. (11) & $\begin{array}{l}1300,1350,1380,1400,1430 \\
1450,1500,1600\end{array}$ & 20 & 20 \\
\hline 6 & Eq. (8) & Eq. (9) & Eq. (10) & Eq. (11) & 1350 & $\begin{array}{l}10,20,30,40,50 \\
60,70,80\end{array}$ & 20 \\
\hline 7 & Eq. (8) & Eq. (9) & Eq. (10) & Eq. (11) & 1350 & 20 & $\begin{array}{l}10,20,30,40,50 \\
60,70,80\end{array}$ \\
\hline
\end{tabular}

\subsection{Comparison with analytical solutions and experimental data}

Due to limitations of the testing condition, only displacement with different voltages could be obtained by experimental methods. And installation of Situ test equipment is shown in Fig. 7 [30]. Since internal values of temperature and stresses are also necessary for detecting failures, analytical solutions based on physical and energy functions from Eqs. (1)-(8) are considered as comparison data for validation of multiphysics modeling. They have been experimentally validated in literatures [6,7]. In this research, analytical solutions are achieved by Matlab Programme because of its nonlinear and double integral.

Thus, to demonstrate the efficiency and feasibility of the proposed approach, two groups of data were employed to verify the multiphysics model by a set of figures: (i) comparisons of temperature, stress and tip deflection value with validated analytical solutions and experimental data from $U=1 \mathrm{~V}$ to $10 \mathrm{~V}$ (shown in Fig. 8(a)-(c)); (ii) comparisons of temperature distribution along the length of "hot" arms, $L_{h 1}$ and $L_{h 2}$, with analytical solutions (shown in Fig. 8(e) and (f)). The power dissipated in a resistor is always proportional to $U^{2}$. So the temperature is also proportional to $U^{2}$ which explains the parabola observed in Fig. 8(a)-(c). From Fig. 8(e)-(f), it could be found that the temperature is largely uniform at the middle of arms except near the ends, which is coincident with the conclusions in [27]. Results of comparison demonstrate that this multiphysics model is acceptable for analysis.

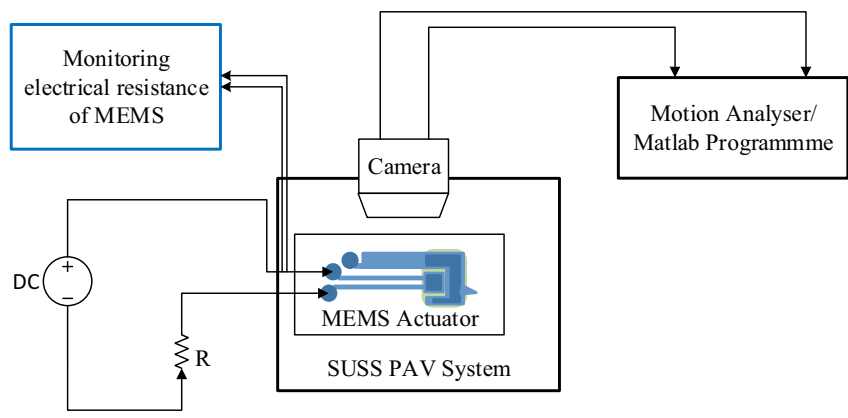

Fig. 7. Sketch of situ test equipments.

\section{Results and discussion}

The described modeling procedure produces various results including performance and failure behaviors to estimate the actuator's reliability. The temperature, thermal stresses, strains and bending of this thermal actuator caused by the applied voltage for both normal and failed states are discussed. The characteristics of the thermal actuator could be used to guide the design and manufacture process.

\subsection{Effect of residual stresses on $\mu E T M A$}

Introduction of pre-stress into developed multiphysics model makes it possible to study its effect on stress and tip deflection. For severe situations, residual stresses are modeled as compressive stress with a magnitude of $100 \mathrm{MPa}$ in silicon and tensile stress with a magnitude of $75 \mathrm{Mpa}$ in a deposited nickel layer. At this condition, thermal expansion is shown in Fig. 9(b), compared with non-residual stress mode (Fig. 9(a)). A significant difference of von Mises stresses has illustrated that severe residual stress degrades the performance of $\mu$ ETMA in great extent.

A special set of simulations dealt with the effect of the magnitude of manufacturing-induced residual stresses on performance of the $\mu$ ETMA (see Fig. 10). Apparently, low residual stresses do not have a significant effect on performance of $\mu$ ETMA. Hence some levels of residual stress could be tolerant, but beyond the threshold it would not function properly. Plastic deformation will rise and change the distribution of strain-stress.

\subsection{Analysis of thermal fatigue}

Three cases were analyzed: (i) without residual stresses, (ii) low residual stresses and (iii) high residual stresses. Fatigue lifetime is computed according to Eq. (13). Reliable strain changes in the Coffin-Manson rule can be obtained from multiple thermal cycles calculations since the metal layers undergo complex plastic deformation. At the present stage of this research ten cycles have been simulated. The equivalent plastic strain is $\Delta \bar{\varepsilon}^{p l}$ defined by the following relationship: 


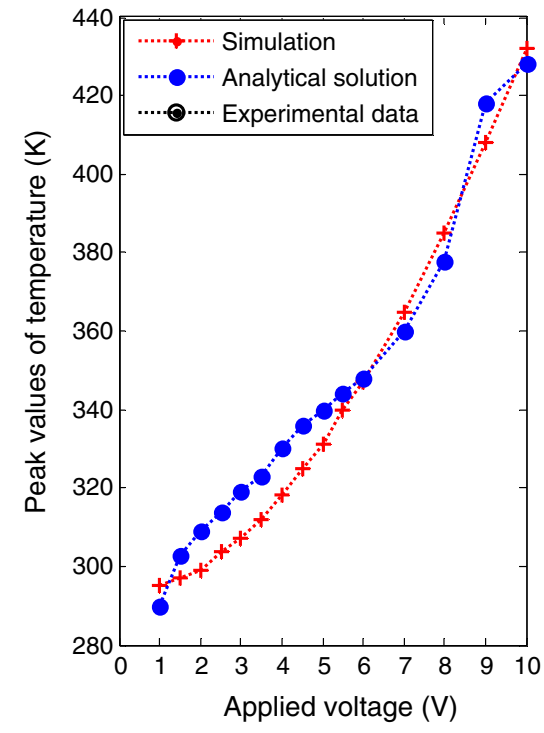

(a)

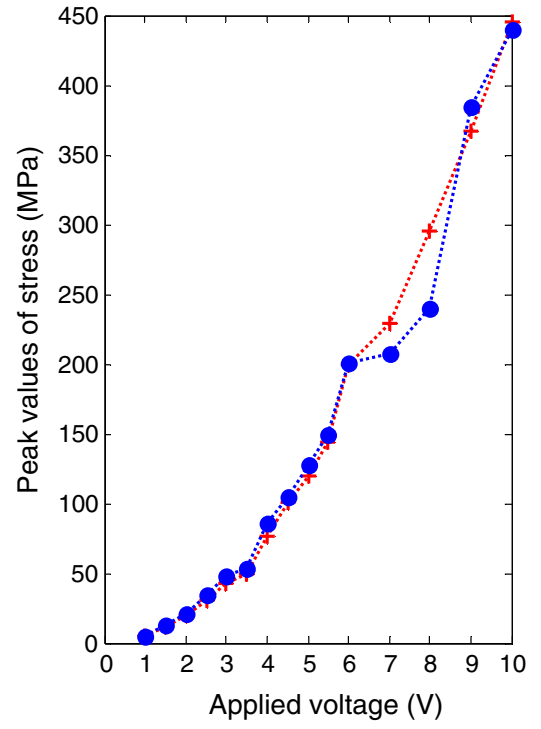

(b)

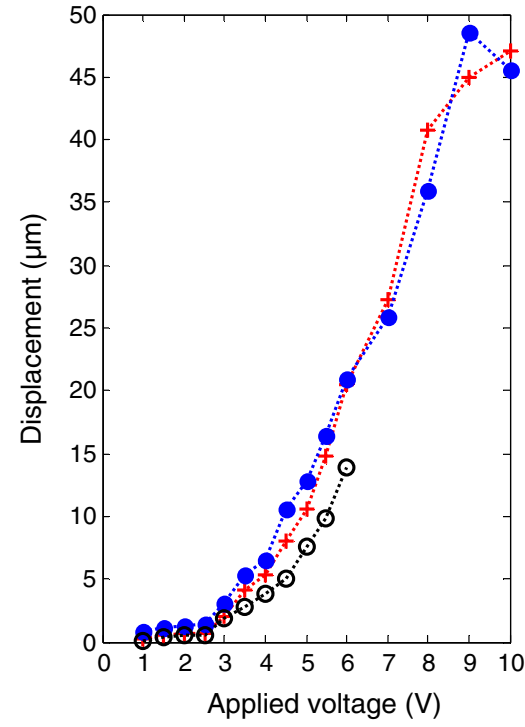

(c)

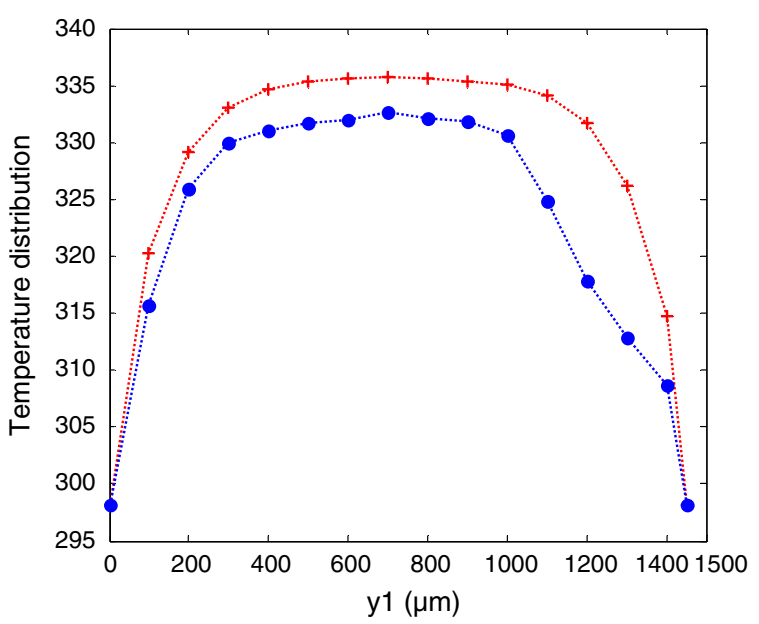

(e)

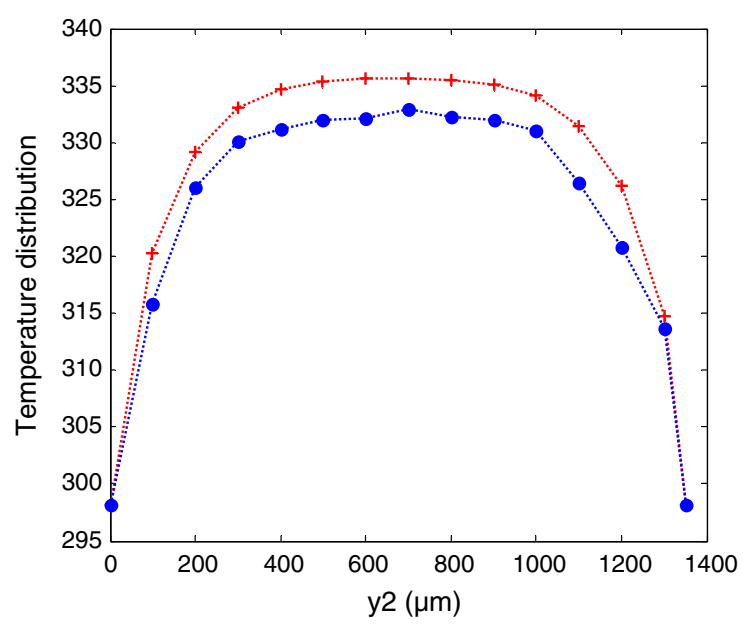

(f)

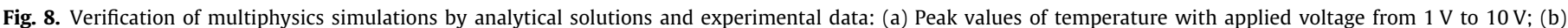

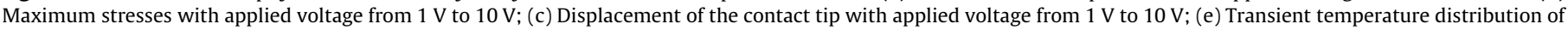
$L_{h 1}$ at $U=5 \mathrm{~V}$ and $t=t^{+}$for type I boundary conditions; (f) Transient temperature distribution of $L_{h 2}$ at $U=5 \mathrm{~V}$ and $t=t^{+}$for type I boundary conditions.

$\Delta \bar{\varepsilon}^{p l}=\left.\Delta \bar{\varepsilon}^{p l}\right|_{0}+\int_{0}^{t} \Delta \dot{\bar{\varepsilon}}^{p l} d t$

where $\left.\Delta \bar{\varepsilon}^{p l}\right|_{0}$ is the initial equivalent plastic strain, and for classical metal plasticity (von Mises):

$\Delta \dot{\bar{\varepsilon}}^{p l}=\sqrt{\frac{2}{3} \dot{\varepsilon}^{p l}: \dot{\varepsilon}^{p l}}$

where $\dot{\varepsilon}^{p l}$ represent the plastic strain rate tensor. The plastic magnitude $\Delta \varepsilon^{p l}$ is defined by

$\Delta \varepsilon^{p l}=\sqrt{\frac{2}{3} \varepsilon^{p l}: \varepsilon^{p l}}$

The comparison of obtained results (in Table 5) shows a pronounced effect of residual stresses on life estimation for the $\mu$ ETMA. In a process of changing the state of the actuator between "On" and "OFF", residual stresses play a negative role in its thermal bending, accelerating plastic deformation and affecting detrimentally its reliability.

\subsection{Effect of electrical overstress on $\mu E T M A$}

Another study of this multiphysics model focused on the effect of electrical overstresses shows stress concentration and tip deflection increase greatly with electrical voltage. Still, it is difficult to assess a precise effect of this overstress on reliability of the actuator. Since it will cause great changes of "hot" arms in geometry and material properties, even some serious faults, such as break of "hot" arms due to high temperature ( $1235 \mathrm{~K}$ when applied voltage is $15 \mathrm{~V}$ ). But it has obvious effect on fatigue lifetime by introducing plastic deformation. Three cases are designed and evaluation results of fatigue lifetime are shown in Table 6. From that, it is easily found that when the actuator works in over-stress situation, its lifetime dramatically reduces.

\subsection{Analysis of parameter sensitivity}

These studied combinations of geometries, material's yielding/plastic hardening, fatigue properties and residual stresses were considered in multiphysics modeling. Then, according to the 

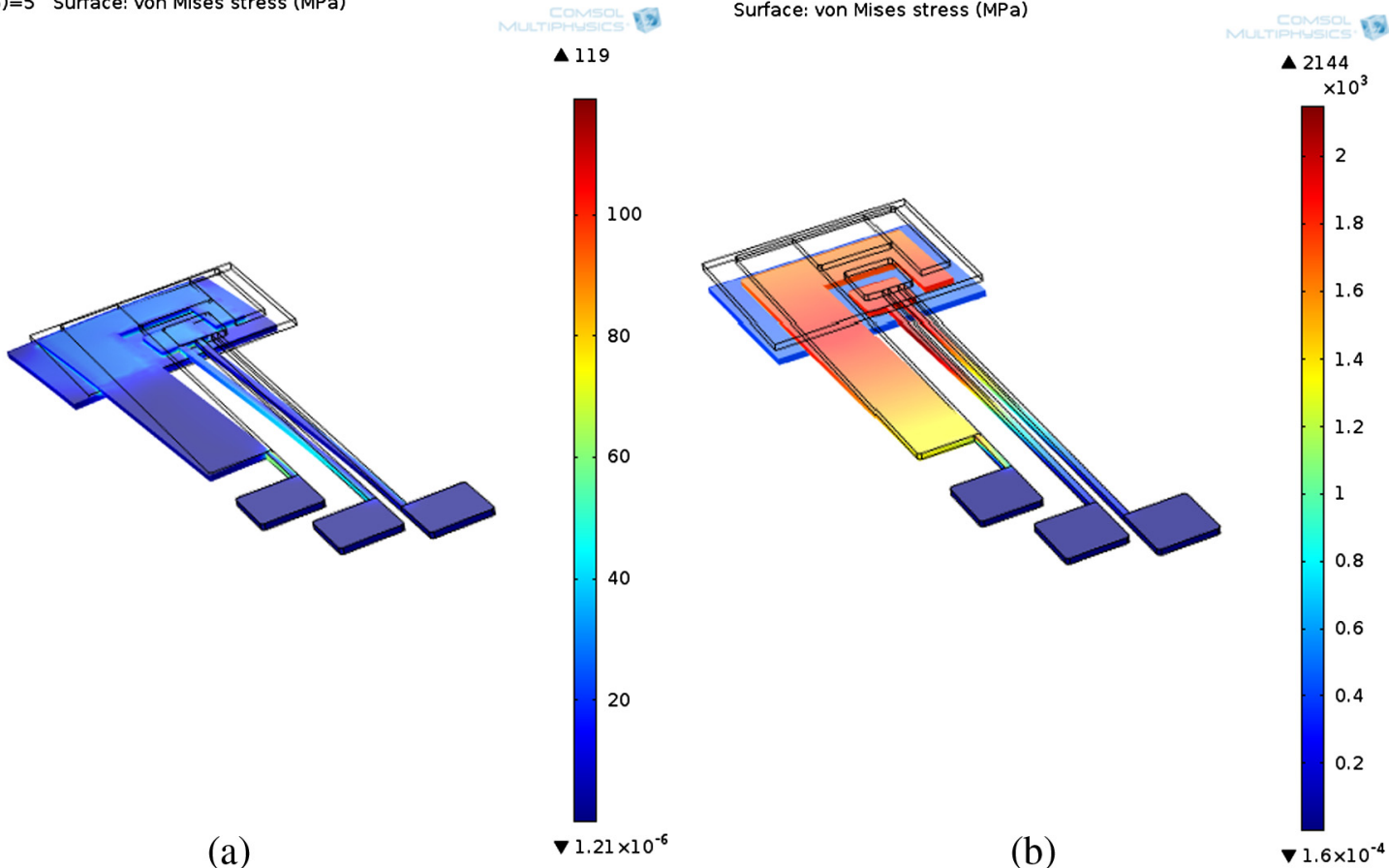

Fig. 9. Effective stress (in MPa) and thermal expansion in $\mu$ ETMA without account for residual stresses (a) and with it (b).

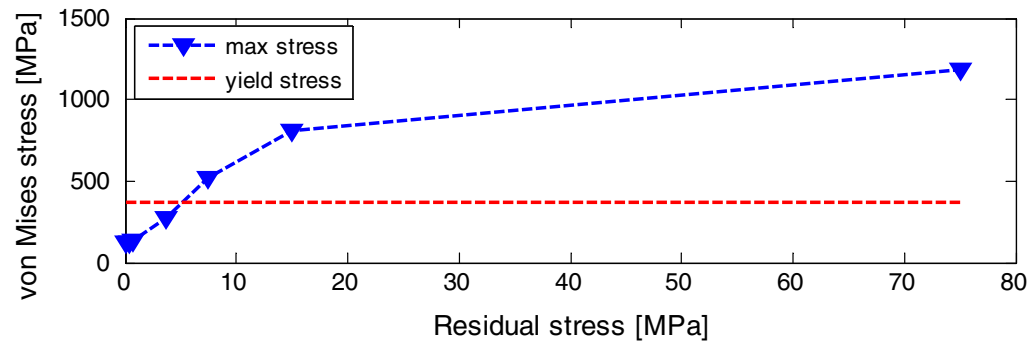

(a)

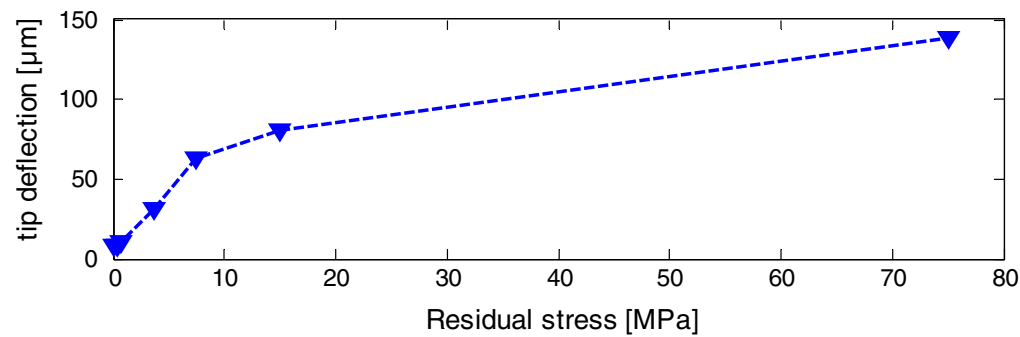

(b)

Fig. 10. Performance of micro actuator with different residual stresses: (a) Von Mises stress; (b) tip deflection.

Table 5

Fatigue lifetime estimation under residual stress.

\begin{tabular}{lllc}
\hline Residual stresses & Maximum $\Delta \varepsilon^{p l}(\%)$ & Parameter $c$ & Fatigue life $N_{f}$ \\
\hline None & 0.32 & -0.5 & 15,625 \\
& & -0.7 & 997 \\
$15 \mathrm{MPa}$ (tensile) & 2.41 & -0.5 & 275 \\
$20 \mathrm{MPa}($ Compressive) & & -0.7 & 56 \\
$75 \mathrm{MPa}$ (tensile) & 3.52 & -0.5 & 130 \\
$100 \mathrm{MPa}$ (Compressive) & & -0.7 & 33
\end{tabular}

Table 6

Fatigue lifetime estimation under over-stress.

\begin{tabular}{lllc}
\hline Electrical voltage & Maximum $\Delta \varepsilon^{p l}(\%)$ & Parameter $c$ & Fatigue life $N_{f}$ \\
\hline $5 \mathrm{~V}$ & 0.32 & -0.5 & 15,625 \\
& & -0.7 & 997 \\
$10 \mathrm{~V}$ & 0.95 & -0.5 & 1772 \\
& & -0.7 & 210 \\
$15 \mathrm{~V}$ & \multirow{2}{*}{1.78} & -0.5 & 506 \\
& & -0.7 & 86
\end{tabular}




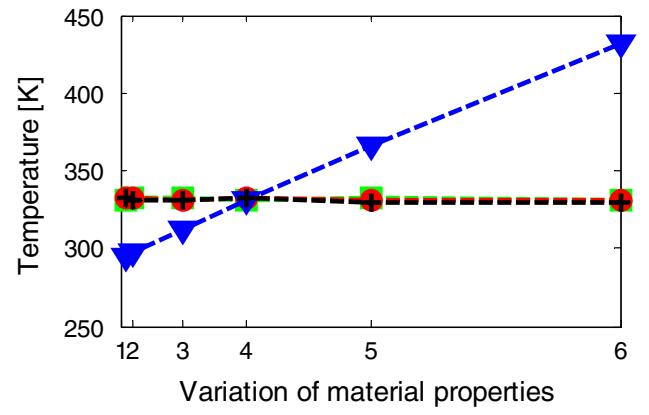

(a)

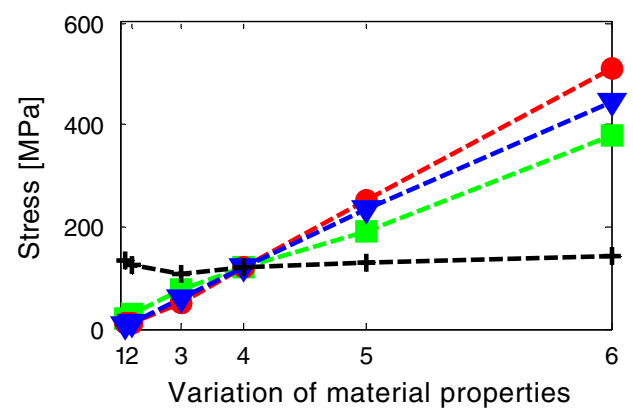

(c)

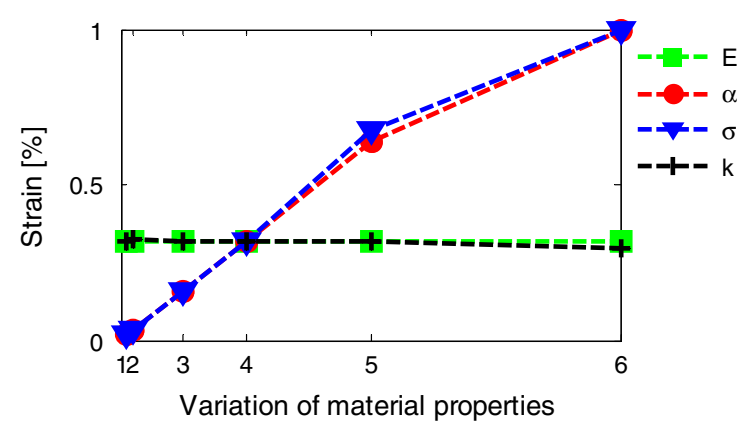

(b)

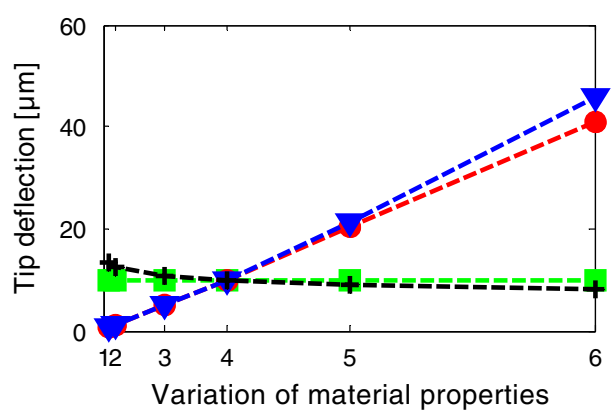

(d)

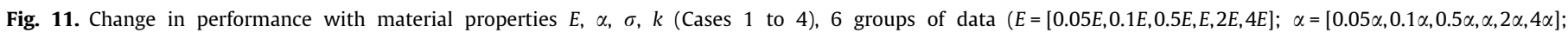
$\sigma=[0.05 \sigma, 0.1 \sigma, 0.5 \sigma, \sigma, 2 \sigma, 4 \sigma] ; k=[0.05 k, 0.1 k, 0.5 k, k, 2 k, 4 k])$ : (a) maximum temperature; (b) maximum strain; (c) maximum stress; (d) tip deflection. See also Table 4 .

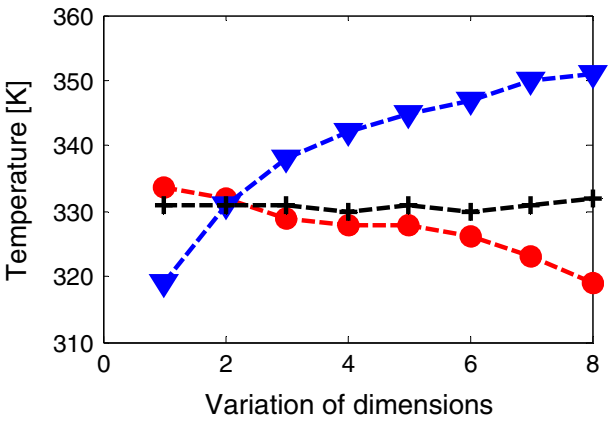

(a)

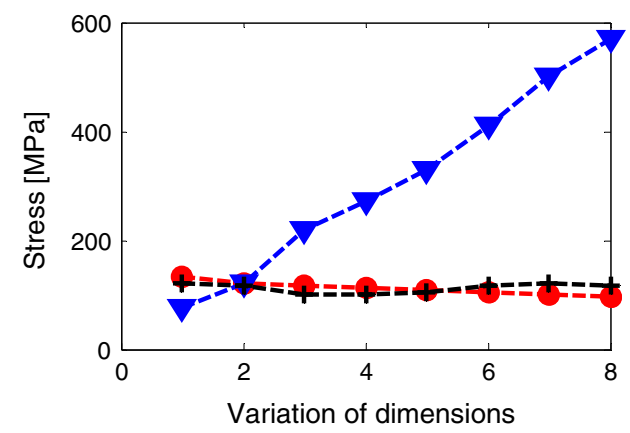

(c)

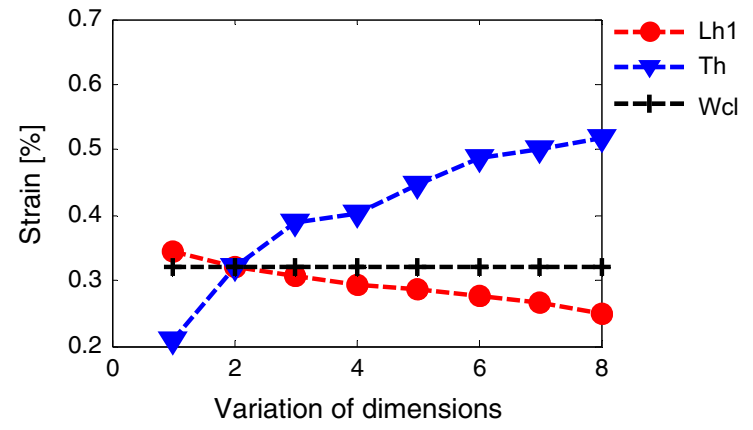

(b)

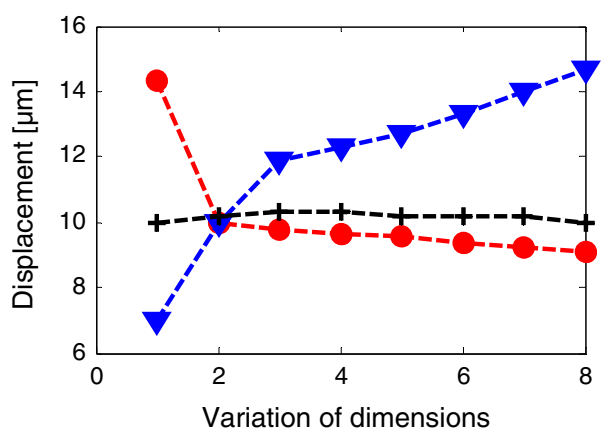

(d)

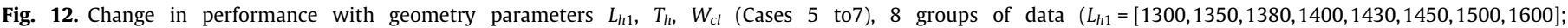

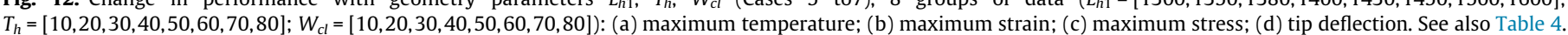

Section 4.2.5, seven groups of experiments were designed for sensitivity analysis, Cases 1 to 7 . Although the tip deflection is the main concern for $\mu$ ETMA users, distribution of temperature, maximum stress and strain can also affect performance and reliability of the $\mu$ ETMA. Thus, their combinations were used to determine the sensitivity of $\mu$ ETMA's service to various parameters. The results of simulation for Cases 1 to 4 are shown in Fig. 11, while those for Cases 5 to 7 are given in Fig. 12. 
From Fig. 11, it is obvious that integrated performance of the $\mu$ ETMA is more sensitive to the coefficient of thermal expansion $\alpha$ and electrical conductivity $\sigma$, reflecting real-life observations. The sensitivity factors of variables $\alpha$ and $\sigma$ are computed with Eq. (14): $S_{\alpha \_ \text {Temperature }}=0 ; S_{\alpha \_ \text {strain }}=0.52 ; S_{\alpha \_ \text {stress }}=0.53 ; \quad S_{\alpha \_ \text {deflection }}=$ $0.79 ; \quad S_{\sigma \_ \text {Temperature }}=0.0046 ; \quad S_{\sigma \_s t r a i n}=0.67 ; \quad S_{\sigma_{-s} \text { tress }}=0.74$; $S_{\sigma_{-} \text {deflection }}=0.99$. That suggests that design engineers could implement desired function by adjusting the two properties. Simultaneously, some failure behaviors, thermal fatigue and plastic deformation could occur with the increasing values of $\alpha$ and $\sigma$. Thus, there should be a balance between the desired performance and requirements of reliability.

Analysis from Cases 5 to 7 (seen in Fig. 12) demonstrates that performance and reliability of the $\mu$ ETMA tend to change more with the "hot" arm's thickness $T_{h}$. The sensitivity factor of $T_{h}$ is $S_{T h \_ \text {Temperature }}=0.01 ; \quad S_{T h \_ \text {strain }}=0.21 ; \quad S_{T h \_s t r e s s}=0.96 ; \quad S_{T h \_d e f l e c t i o n}=$ 0.15 . Maximum thermal stresses are significantly affected by variations of thickness $T_{h}$. This could be accommodated with special design aimed at decreasing plastic deformation of materials and preventing the $\mu$ ETMA from other failures.

\section{Conclusions}

Reliability of the $\mu$ ETMA becomes of vital importance due to its wide application areas and demanding environmental conditions. Still, detection of its failures could not explain how they affect actuators' performance. Thus, a good FMMEA is necessary to obtain an exhaustive taxonomy of failure mechanisms and effects, examine critical failure modes and prioritize their modeling; for instance residual stresses, plastic deformation, electrical overstress and thermal fatigue in $\mu$ ETMA case. A failure mechanisms-coupled multiphysics modeling approach is then studied to assess reliability and change in performance of devices. The obtained simulation results demonstrated the efficiency and feasibility of the suggested method.

Failure mechanisms-coupled analysis could provide important recommendations for the design of better micro-devices before fabrication: (i) Its manufacturing process should be carefully designed to achieve tolerable levels of residual stresses, depending on its application conditions; (ii) For long term applications actuators should be driven lightly; (iii) Excitation should allow the actuator to cool down and dissipate heat between consequent cycles; (iv) Sensitively select coefficient of thermal expansion, electrical conductivity and thickness of "hot" arms will help improve the performance of $\mu$ ETMA.

Additionally, the planned future work will extend this study to account for a detailed multilayer structure in order to refine analysis of concentration of maximum stresses and analyze potential failure phenomena, for instance, interface delamination between different materials, fracture due to micro-cracks and plastic deformation of different layers under conditions of thermal fatigue. Eventually, a complete failure mechanisms-coupled analysis of the $\mu$ ETMA will be implemented for its reliable design.

\section{Acknowledgments}

This work was jointly supported by the Mechanics of Advanced Materials research group in Loughborough University, UK and Science and Technology on Reliability and Environmental Engineering Laboratory in Beihang University, China. J. Wang would like to thank the Chinese Scholarship Council, China, for financial assistance.

\section{References}

[1] Chen W, Chu C, Hsieh J, Fang W. A reliable single-layer out of plane micromachined thermal actuator. Sens Actuat A 2003;103(1):48-58.

[2] Colin M, Dhennin J, Coccetti F, et al. Deliverable D4-manufacturing; 6.19.2009. p. 8-16.

[3] Zhu Y, Corigliano A, Espinosa HD. A thermal actuator for nanoscale in situ microscopy testing: design and characterization. J Micromech Microeng 2006;16(2):242-53.

[4] Wilson SA, Jourdain RPJ, Zhang Q, et al. New materials for micro-scale sensors and actuators: an engineering review. Mater Sci Eng: R: Rep 2007;56(16):1-129.

[5] Huang Q Lee NKS. Analysis and design of polysilicon thermal flexure actuator J Micromech Microeng 1999;9(1):64-70.

[6] Jiang J. Electro-thermal analytical modelling of multilayer cantilever microactuator. Trans Beijing Inst Technol 2005;25(6):512-6 [in Chinese].

[7] Jiang J, Hilleringmann U, Shui X. Electro-thermo-mechanical analytical modelling of multilayer cantilever microactuator. Sens Actuat A 2007; 137(2):302-7.

[8] Yan D, Khajepour A, Mansour R. Modelling of two-hot-arm horizontal therma actuator. J Micromech Microeng 2003;13(2):312-22.

[9] Spengen WMV. MEMS reliability from a failure mechanisms perspective. Microelectron Reliab 2003;43(7):1049-60.

[10] Baker MS, Plass RA, Headley TJ, Walraven JA. Final report: compliant thermomechanical MEMS actuators LDRD \#52553. Sandia report SAND2004-6635; printed December 2004.

[11] Lin TH, Paul S, Lu S, Lu H. A study on the performance and reliability of magnetostatic actuated RF MEMS switches. Microelectron Reliab 2009;49(1):59-65.

[12] Zhang W, Meng G, Li H. Electrostatic micromotor and its reliability Microelectron Reliab 2005;45(7-8):1230-42.

[13] Vallett DP. Failure analysis requirements for nanoelectronics. IEEE Trans Nanotechnol 2002;1(3):117-21.

[14] Muratet S, Lavu S, Fourniols J, et al. Reliability modelling and analysis of thermal MEMS. J. Phys.: Conf. Ser. 2006;34(1):235-40.

[15] Matmat M, Coddetti F, Marty A, et al. Capacitive RF MEMS analytical predictive reliability and lifetime characterization. Microelectron Reliab 2009;49(911):1304-8.

[16] Melle S, Conto DD, Dubuc D, et al. Reliability modelling of capacitive RF MEMS IEEE Trans Microwave Theo Tech 2005;53(11):3482-8.

[17] Kuenzig T, Schrag G, Iannacci J. Modelling and simulation of an active restoring mechanism for high reliability switches in RF-MEMS technology. Microelectron Reliab 2012;52(9-10):2235-9.

[18] Maligno AR, Whalley D, Silberschmidt V. A three-dimensional (3D) numerical study of fatigue crack growth using remeshing techniques. Eng Fract Mech 2010;77(1):94-111.

[19] Maligno AR, Whalley D, Silberschmidt V. Interfacial failure under thermal fatigue loading in multi-layered MEMS structure. Mater Sci Eng 2010;10(1):1-9.

[20] Maligno AR, Whalley DC, Silberschmidt VV. Thermal fatigue life estimation and delamination mechanics studies of multi-layered MEMS structures. Microelectron Reliab 2013;52(8):1665-78.

[21] Dhennin J, Lellouchi D. Implementation of physics of failure for MEMS POLYNOE program. Document reference: TR-WP7.2-001; 2009.

[22] Cowen A. MetalMUMPs design handbook. Revision 1.0 MEMScAP; 2002.

[23] Venkatachalam A, James WT, Graham S. Electro-thermo-mechanical modelling of GaN-based HFETs and MOSHFETs. Semicond Sci Technol 2011;26(8):1-6.

[24] Chen RT, Nguyen H, Wu MC. A low voltage micro-machined optical switch by stress-induced bending. IEEE Photonics Technol Lett 1999;11(11):1396-8.

[25] Careslaw HS, Jaeger JC. Conduction of heat in solids. Oxford University Press; 1959.

[26] Han LH, Lu TJ. Modelling and optimal design of multilayer cantilever microactuators. Mater Res Soc Symp Proc 2004;795:1-6.

[27] Lu TJ, Hutchinson JW, Evans AG. Optimal design of a flexural actuator. J Mech Phys Solids 2001;49(9):2071-93.

[28] Lin L, Chiao M. Electrothermal responses of lineshape microstructures. Sens Actuat A 1996;55(1):35-41.

[29] De Wolf I, Czarnecki P, Jourdain A, et al. Failure mechanisms and reliability issues of RF-MEMS switches. IMEC 2005.

[30] Desmulliez MPY, Lavu S, Begbie M, et al. Reliability simulation methodology and support for FMEA application to electrothermal flexure actuators. Final Technical Review Patent DfMM, Lancaster; 2007.

[31] Fonseca DJ, Sequera M. On MEMS reliability and failure mechanisms. Int J Qual Statist Reliab 2011;2011:1-7.

[32] Powell RW, Tye RP, Hickman MJ. The thermal conductivity of nickel. Int J Heat Mass Transf 1965;8(5):679-88.

[33] Online materials information resource-MatWeb <www.matweb.com>.

[34] Liu G, Oh S. A Stress induced Thermal actuator for optical purpose. University of California <http://citeseerx.ist.psu.edu/viewdoc/summary?doi=10.1.1.123. $\underline{6651>}$

[35] Weinberg K, Muller WH. A strategy for damage assessment of thermally stressed copper vias in microelectronic packaging. Microelectron Reliab 2008;48(1):68-82. 